\title{
A Survey of blood types of the Domestic cat (Felis catus) in Maiduguri, North-eastern Nigeria
}

Bukar-Kolo Yachilla Maryam¹, Balami Arhyel Gana ${ }^{1 *}$, Geidam Yaqub Ahmed ${ }^{1}$, Wakil M Abubakar ${ }^{2}$ and Shuibu Istifanus ${ }^{1}$

${ }^{1}$ Department of Veterinary Medicine, Faculty of Veterinary Medicine, University of Maiduguri, Nigeria

${ }^{2}$ Department of Veterinary Physiology, Pharmacology and Biochemistry, Faculty of Veterinary Medicine, University of Maiduguri, Nigeria

\begin{abstract}
A haematological study was carried out in domestic cats native to Nigeria, in Maiduguri, north-eastern Nigeria. The aim was to determine the blood types in this specie (AB blood system) using the CHROM method which is based on immunochromatograhic diffusion of RBC's passing through monoclonal antibody containing strips (Alvedia Quick test kit). Fifty cats were sampled and analysed. The result showed that cats with blood type A were the most common with a rate of $44 / 50(88 \%)$, followed by type B $6 / 50$ (12\%). Of all the cats sampled, none had blood type AB. This study documents the first record of blood types in cats in Nigeria. The knowledge of the blood group of the domestic cats has significant clinical implications in terms of transfusion medicine as well as for breeding purposes.
\end{abstract}

Keywords: Domestic cats; $\mathrm{AB}$ blood system; Maiduguri; Nigeria; Alvedia test kit

\section{Introduction}

The $\mathrm{AB}$ system has been identified as the major blood group system in the domestic cat and includes types $\mathrm{A}, \mathrm{B}$ and $\mathrm{AB}[1]$. Recently, the Mik red cell antigen was recognized [2]. Cats differ from dogs in that they are born with naturally occurring alloantibodies [3]. An example is neonatal isoerythrolysis which may be seen in kittens born to a queen with a different blood type. This clinical condition commonly occurs when kittens of type A nurse from mother of type B [3].

The type A kitten absorbs antibodies contained in the colostrums of the mother for approximately the first 24 hours after birth [4]. Blood types are differentiated by genetically determined glycolipid and glycoprotiens on the red blood cell membrane [5]. Sera of either type A or type $B$ cats have naturally occurring isoagglutinins to the opposite blood type. Blood type $\mathrm{AB}$ cats do not contain anti-A or $-\mathrm{B}$ isoagglutinins. The anti $-\mathrm{A}$ isoantibodies in type $\mathrm{B}$ cats are highly agglutinating and hemolytic to both blood type $A$ and $A B$ [6]. Although, Cats with blood group $\mathrm{AB}$ are rare and do not have anti-B anti bodies and are thus universal recipient for blood transfusion [1], however, there is no universal donor in cats. Therefore, performing a cross matching of blood before any transfusion is now very essential in light of the clinical relevance of naturally occurring anti-mik alloantibodies and potentially additional alloantibodies [2].

The incidence of the $\mathrm{AB}$ blood group system varies among cat breeds and geographic locations [7]. Type A has been found to be the most common blood type in the domestic cat. However, the frequency of type $\mathrm{AB}$ was found to be consistently very rare $[7,8]$.

The determination of the $\mathrm{AB}$ blood type has been simplified by the availability of the in-clinic typing system [9]. There are now several available serological test kits for typing of the feline blood. This include the CARD method consisting of a card with wells containing lyophilized monoclonal anti- A or anti-B antibody [10], the GEL method in which the agglutination in matrix gel columns containing serum or lactins are examined [7]. For the purpose of this study, the CHROM method of blood typing using Alvedia quick test kits was used due to its simplicity, and has a record of $95 \%$ success when compared with other typing methods [9]. Blood typing and cross matching are important prerequisite for successful blood transfusion. Transfusion of whole blood or blood components is indicated in several clinical situations [11]. The domestic cats' native to Nigeria have not been categorised into breeds and are considered mongrels. More so, feline practice is gaining recognition in the study area; however, there is a dearth of information on the blood groups of indigenous domestic cats in Nigeria. This study was designed to determine the blood types $(\mathrm{A}, \mathrm{B}$ and $\mathrm{AB})$ of these cats.

\section{Materials and Methods}

\section{Study area}

The study was carried out in Maiduguri metropolis, the capital city of Borno State, northeastern Nigeria. The state lies between latitudes $11^{\circ} 32^{\prime}$ and $11^{\circ} 40^{\prime}$ north and longitudes $13^{\circ} 32^{\prime}$ and $13^{\circ} 25^{\prime}$ east and located between the Sudan savannah and Sahel savannah vegetation zones [12].

\section{Study animals}

Fifty (Pets and Stray) domestic cats native to Nigeria were randomly selected from different locations in Maiduguri metropolis and sampled for elective blood typing from October-December, 2011 in accordance with the guidelines for the care and use of animals by the National Research Council (NRC). Twenty seven of these cats were males and twenty three were females. The cats were aged between 6 months to 5 years. All the cats sampled were entire and had access to the outdoor. The stray cats $(n=15)$ were obtained from public places like abattoir, fish markets and hospitals. The cats were restrained properly; $2 \mathrm{ml}$ of blood was aseptically collected by jugular venapuncture and placed in plastic tubes containing EDTA and transported on ice to the laboratory. Blood typing was performed within twenty four (24) hours

*Corresponding author: Balami Arhyel Gana, Department of Veterinary Medicine, Faculty of Veterinary Medicine, University of Maiduguri, Nigeria, Tel: +2348067703103; E-mail: talktoarrow@yahoo.com

Received November 28, 2013; Accepted January 04, 2014; Published January 06, 2014

Citation: Maryam BKY, Gana BA, Ahmed GY, Abubakar WM, Istifanus S (2014) A Survey of blood types of the Domestic cat (Felis catus) in Maiduguri, North-eastern Nigeria. J Veterinar Sci Technol 5: 152. doi:10.4172/2157-7579.1000152

Copyright: (C) 2014 Maryam BKY, et al. This is an open-access article distributed under the terms of the Creative Commons Attribution License, which permits unrestricted use, distribution, and reproduction in any medium, provided the original author and source are credited. 
using. immunochromatographic cartridge (Alvedia quick test kit) strictly following the manufacturer's instructions. The test is based on incorporation of two monoclonal antibodies specific to the $\mathrm{A}$ and $\mathrm{B}$ antigens on a membrane. These monoclonal antibodies will retain A/ $\mathrm{B}$ or both red blood cells, producing red bands on the mid portion of the membrane. The presence of a red band at the position marked $\mathrm{C}$ (control) had to be present for result interpretation, the existence of a visible red band at the position marked $\mathrm{A}$ indicated the expression of the $\mathrm{A}$ antigen, and the presence of a red band at the $\mathrm{B}$ position indicated expression of the B antigen on RBCs.

\section{Statistics}

Statistical analysis was performed using Fisher's exact test using Graph pad instant version 3.05 for windows (Graph pad software). Sample prevalence was calculated as percentages. $\mathrm{P}<0.05$ was considered significant.

\section{Results}

Out of the fifty cats examined in this study, the result showed that blood type A had the highest frequency $44 / 50(88 \%)$ followed by type $B$ $6 / 50(12 \%)$ and none of the cats tested were positive for blood type $A B$ (Table 1). The frequency of blood type $B$ was also found to be significant $(\mathrm{P}<0.05) 4 / 50(8 \%)$ between the females and the males.

\section{Discussion}

Information regarding blood types of the domestic cats' native to Nigeria is not available. This study is the first to document blood types of domestic cats indigenous to Nigeria. The result showed that blood group A is the most common type observed in the current study. This observation is in conformity with reports of similar studies conducted in U.K, Finland and Dublin $[13,14]$. Several other studies from different countries have previously demonstrated that type $\mathrm{A}$ is the most common blood type in the domestic house cat $[7,15,16]$. Relative to the A blood type, the B blood type observed in the present study is small (12\%), with frequency similar to what was reported in non-pedigree cats $[14,15]$ but lower to those observed by Gurkan et al. [17] in Turkish van and Angora breeds, and Arikan et al. [18] in non-pedigree cats. Also when transfusing blood from a type A cat to a type B cat, may result in severe transfusion reaction which may likely result in fatality [14]. Because cats with type B blood have high titres of naturally occurring anti-A haemagglutinins and haemolysins, mainly of IgM class with very little amount of IgG [14]. However, the value in the current study is higher than the $2.9 \%$ reported by Medeiros et al. [5]

From the findings in the present study, none of the cats sampled had type $A B$ blood probably due to the sample size or it may have confirms previous report of its rarity [19]. It has generally been reported that the type $\mathrm{AB}$ blood is very rare [1]; studies from the UK and the USA put it at $5 \%$ and $1 \%$, respectively. However, in a recent study with Ragdoll, Proverbio et al. [20] recorded a higher prevalence of $18 \%$.

The significance of feline blood typing cannot be overemphasized. Cats' ownership is gaining popularity in the study area, therefore

\begin{tabular}{|c|c|c|c|}
\hline Gender & \multicolumn{3}{|c|}{ Blood Type } \\
\hline & $\mathbf{A}(\%)$ & $\mathrm{B}(\%)$ & $\mathrm{AB}(\%)$ \\
\hline Male & $25(50)$ & $2(4)$ & $0(0)$ \\
\hline Female & $19(38)$ & $4(8)$ & $0(0)$ \\
\hline Total & $44(88)$ & $6(12)$ & $0(0)$ \\
\hline
\end{tabular}

( ) = Numbers in parenthesis are percentages

Table 1: Blood Types of domestic cats native to Nigeria. understanding the blood types of these cats is of paramount importance in terms of transfusion medicine which may limit the risk of transfusion reaction and also neonatal isoerythrolysis, when cats of different blood types are bred [21]. This study has shown that the blood types of domestic cats indigenous to Nigeria were the $\mathrm{A}$ and $\mathrm{B}$ types, with the $\mathrm{A}$ blood type being the most common. Blood type $\mathrm{AB}$ was not found in this study. It is therefore suggested that blood typing and cross matching should be performed before any blood transfusion is done so as to avoid the occurrence of adverse reactions. It is also recommended that kittens should be blood typed, and be separated from the queen for 24 hours if the queen is type $\mathrm{B}$ blood type and kitten are type $\mathrm{A}$ or $\mathrm{AB}$ to prevent the risk of neonatal isoerythrolysis [22].

\section{References}

1. Bighignoli B, Niini T, Grahn RA, Pedersen NC, Millon LV, et al. (2007) Cytidine monophospho- $\mathrm{N}$-acetylneuraminic acid hydroxylase (CMAH) mutations associated with the domestic cat AB blood group. BMC Genet 8: 27.

2. Weinstein NM, Blais MC, Harris K, Oakley DA, Aronson LR, et al. (2007) A newly recognized blood group in domestic shorthair cats: the Mik $r$ cell antigen J Vet Intern Med 21: 287-292.

3. Silvestre-Ferreira AC, Pastor J (2010) Feline neonatal isoerythrolysis and the importance of feline blood types. Vet Med Int 2010: 753726.

4. Casal ML, Jezyk PF, Giger U (1996) Transfer of colostral antibodies from queens to their kittens. Am J Vet Res 57: 1653-1658.

5. Medeiros MA, Soares AM, Alviano DS, Ejzemberg R, da Silva MH, et al. (2008) Frequencies of feline blood types in the Rio de Janeiro area of Brazil. Vet Clin Pathol 37: 272-276.

6. Griot-Wenk ME, Callan MB, Casal ML, Chisholm-Chait A, Spitalnik SL, et al (1996) Blood type $A B$ in the feline $A B$ blood group system. Am J Vet Res 57 1438-1442.

7. Lapierre Y, Rigal D, Adam J, Josef D, Meyer F, et al. (1990) The gel test: a new way to detect red cell antigen-antibody reactions. Transfusion 30: 109-113.

8. Giger U, Griot-wenk M, Bucheler J (1991) Geographical Variation on Feline Blood Type Frequencies in the United States. Feline pract 19:21-27.

9. Seth M, Jackson KV, Giger U (2011) Comparison of five blood-typing methods for the feline AB blood group system. Am J Vet Res 72: 203-209.

10. Stieger K, Palos H, Giger U (2005) Comparison of various blood-typing methods for the feline AB blood group system. Am J Vet Res 66: 1393-1399.

11. Guillermo CC (2009) Haematology. In: Small Animal Internal Medicine. 4th Edn Nelson, Couto (ed). Pp 1209

12. Udo RK (1981) Geographical region of Nigeria. Heinemann Education Books Ltd Ibadan, Nigeria 1981. Pp 27.

13. Gunn-Moore DA, Simpson KE, Day MJ (2009) Blood types in Bengal cats in the UK. J Feline Med Surg 11: 826-828

14. Knottenbelt CM, Addie DD, Day MJ, Mackin AJ (1999) Determination of the prevalence of feline blood types in the UK. J Small Anim Pract 40: 115-118.

15. Giger U (1992) The feline AB blood group system and incompatibility reactions. In Current Veterinary Therapy X1: Small Animal practice. (Eds) Kirk R. In Bonogura J.D., W.B Sounders. Pp 470-474

16. Griot-Wenk ME, Giger U (1995) Feline transfusion medicine. Blood types and their clinical importance. Vet Clin North Am Small Anim Pract 25: 1305-1322.

17. Gurkan M, Arikan S, Ozaytekin E, Dodurka T (2005) Titres of alloantibodies against $A$ and $B$ blood types in non-pedigree domestic cats in Turkey: assessing the transfusion reaction risk. J Feline Med Surg 7: 301-305.

18. Arikan S, Gurkan M, Ozaytekin E, Dodurka T, Giger U (2006) Frequencies of blood type A, B and AB in non-pedigree domestic cats in Turkey. J Small Anim Pract 47: 10-13.

19. Arikan S, Duru SY, Gurkan M, Agaoglu ZT, Giger U (2003) Blood type A and $B$ frequencies in Turkish Van and Angora cats in Turkey. J Vet Med A Physiol Pathol Clin Med 50: 303-306.

20. Proverbio D, Spada E, Perego R, Della Pepa A, Bagnagatti De Giorgi G, et al (2013) Assessment of blood types of Ragdoll cats for transfusion purposes. Vet Clin Pathol 42: 157-162. 
Citation: Maryam BKY, Gana BA, Ahmed GY, Abubakar WM, Istifanus S (2014) A Survey of blood types of the Domestic cat (Felis catus) in Maiduguri, North-eastern Nigeria. J Veterinar Sci Technol 5: 152. doi:10.4172/2157-7579.1000152

Page 3 of 3

21. Juvet F, Brennan S, Mooney CT (2011) Assessment of feline blood for transfusion purposes in the Dublin area of Ireland. Vet Rec 168: 352.

22. Proverbio D, Spada E, Baggiani L, Perego R, Milici A, et al. (2011) Comparison of gel column agglutination with monoclonal antibodies and card agglutination methods for assessing the feline $A B$ group system and a frequency study of feline blood types in northern Italy. Vet Clin Pathol 40: 32-39. 